\title{
Cientistas sociais no Sistema Único de Saúde*
}

Nelson Filice de Barros e Rafael Afonso da Silva

Embora seja possível afirmar que existe uma tradição de cientistas sociais trabalhando no campo da saúde no Brasil (Nunes, 1992; 2000; 2003; 2005; 2006; Canesqui, 1995; 1998; 2008; Nascimento, 2011) e em outros países (Straus, 1956; Cockerham, 2005), essa força de trabalho e suas contribuições são praticamente invisíveis. Este artigo discute, com base em investigação empírica, a "invisibilidade" dos cientistas sociais no âmbito do Sistema Único de Saúde (SUS), sem poder, portanto, estender suas conclusões provisórias à atuação desses profissionais em outras áreas da saúde, como a docência e a pesquisa. São analisados os resultados de dois estudos complementares, realizados em 2011 e 2012 por meio de entrevistas telefônicas. O primeiro foi desenvolvido com secretários de saúde dos 645 municípios do estado de São Paulo ou, na sua ausência, com outros profissionais da gestão da saúde, com o objetivo de saber se havia cientistas sociais formalmente contratados na respectiva área e qual era a visão dos gestores sobre suas contribuições. $\mathrm{O}$ segundo, com catorze cientistas sociais trabalhadores de secretarias de saúde de diferentes municípios paulistas, porém, com roteiro semiestruturado de entrevistas, orientado para colher dados de seu processo de formação e seu ingresso no campo da saúde, assim como os sentidos que atribuem ao trabalho sociológico nesse campo. 
A implicação desse estudo alcança diferentes ordens, na medida em que se orienta para a compreensão da práxis de agentes com reconhecida importância na saúde coletiva e limitada tradição na gestão de serviços de saúde e do SUS. Além disso, são fornecidos elementos para problematizar as dimensões sociais da invisibilidade desses agentes, que se envolvem, técnica, política, econômica e culturalmente, na construção e implantação de políticas públicas de saúde no Brasil.

\section{Os cientistas sociais no sus: percepções interprofissionais}

Dos 645 municípios do estado de São Paulo, a pesquisa, por meio de questionário aplicado por via telefônica, contemplou 456 municípios, ou seja, $70,7 \%$ do total. Esse percentual sustenta a possibilidade de generalização dos resultados relativos às percepções sobre o caráter do trabalho dos cientistas sociais na saúde.

Dos 456 entrevistados, 427 informaram dados relativos ao perfil sociodemográfico e profissional. Em relação ao sexo e à idade dos informantes, 254 são mulheres (59,48\%) e 173 homens (40,52\%), com idade média de 41,9 anos e a mediana de 42 anos completos em 31 de dezembro de 2011. Pode-se dizer que o perfil etário mostra profissionais no meio da vida produtiva e que aqueles com mais de 30 anos de idade representam cerca de 90\% dos entrevistados. A Tabela 1 expõe a distribuição da faixa etária em relação ao sexo dos respondentes.

TABELA 1

Perfil etário dos entrevistados (2011)

\begin{tabular}{lcccccc}
\hline IDADE & MUlHeres & $\%$ & HOMENS & $\%$ & TOTAL & $\%$ \\
\hline $20-29$ & 33 & 13,0 & 16 & 9,2 & 49 & 11,5 \\
$30-39$ & 79 & 31,1 & 49 & 28,3 & 128 & 30,0 \\
$40-49$ & 81 & 31,9 & 56 & 32,4 & 137 & 32,1 \\
$50-59$ & 57 & 22,4 & 49 & 28,3 & 106 & 24,8 \\
60 e mais & 4 & 1,6 & 3 & 1,7 & 7 & 1,6 \\
\hline TOTAL & 254 & 100,0 & 173 & 100,0 & 427 & 100,0 \\
\hline
\end{tabular}

Em relação à formação declarada pelos entrevistados, sabe-se que a maioria tem nível superior completo, 282 contra 145 com nível médio. Ao analisar suas formações em relação às grandes áreas da ciência, vemos na Tabela 2 que a maior parte tem formação em profissões abrangidas pela área das ciências humanas. 
TABELA 2

Distribuição dos entrevistados segundo grandes áreas de classificação das ciências (2011)

\begin{tabular}{lcccc}
\hline & MulHeRES & $\%$ & Homens & $\%$ \\
\hline Humanas & 102 & 57,3 & 57 & 54,8 \\
Biológicas & 53 & 29,8 & 24 & 23,1 \\
Exatas & 23 & 12,9 & 23 & 22,1 \\
\hline TOTAL & 178 & 100,0 & 104 & 100,0 \\
\hline
\end{tabular}

Especificamente em relação às ocupações atuais dos entrevistados, observa-se na Tabela 3 que 44,7\% (191) se ocupam da gestão dos recursos humanos do município. Destacam-se igualmente outros dois grupos majoritários: o dos que ocupam funções da administração municipal (71, ou 24,4\%) e o dos que desempenham a função de secretários de saúde do município (65, ou 25,1\%).

TABELA 3

Distribuição dos entrevistados por ocupação (2011)

\begin{tabular}{lcccccc}
\hline OCuPAÇõES & MULHERES & $\%$ & HOMENS & $\%$ & TOTAL & $\%$ \\
\hline Profissionais gestores de recursos humanos & 108 & 41,4 & 83 & 50,0 & 191 & 44,7 \\
Profissionais da administração pública & 71 & 27,2 & 33 & 19,9 & 104 & 24,4 \\
municipal & & & & & & \\
Profissionais da gestão municipal da saúde & 65 & 24,9 & 42 & 25,3 & 107 & 25,1 \\
Profissionais da saúde (nível superior) & 10 & 3,8 & 3 & 1,8 & 13 & 3,0 \\
Profissionais da saúde (nível médio) & 4 & 1,5 & 0 & 0,0 & 4 & 0,9 \\
Outros profissionais & 3 & 1,1 & 5 & 3,0 & 8 & 1,9 \\
\hline Total & 261 & 100,0 & 166 & 100,0 & 427 & 100,0 \\
\hline
\end{tabular}

Esses dados, per se, permitem delinear um perfil mínimo dos entrevistados. Trata-se de um grupo razoavelmente homogêneo, com elevado grau de instrução para os padrões brasileiros e com experiência consolidada no mundo do trabalho, especialmente na gestão da saúde e na gestão pública em geral. Pode-se supor, seja pela formação da maioria, provinda da grande área das ciências humanas, seja pela ocupação exercida, que esse grupo tenha razoável conhecimento sobre a área das ciências sociais.

A questão feita para os 427 entrevistados foi: “O(A) Sr(a). acha importante a presença do cientista social no quadro funcional da sua secretaria?”. Entre os que responderam negativamente, localizamos quatro subcategorias: 1) "desconhece explicitamente essa categoria"; 2) "não é importante de maneira geral"; 3 ) "não é importante em razão de o município ser pequeno"; 4) "não soube responder". Entre as respostas afirmativas, foram identificadas diferentes justificativas, reunidas segundo as subcategorias seguintes: 1) “ajuda”; 2) “com 
funções assemelhadas aos assistentes sociais"; 3 ) "compreensão de problemas complexos".

Dos 427 respondentes, 102 declararam não achar importante ter um cientista social no quadro funcional da sua secretaria. Em termos quantitativos, esse número compreende aproximadamente $24 \%$ do total da amostra. A Tabela 4 apresenta esse dado numérico distribuído nas subcategorias identificadas.

TABELA 4

Distribuição das respostas negativas sobre a importância da função do cientista social em subcategorias

\begin{tabular}{lc}
\hline SUBCATEGORIA & FREQUÊNCIA \\
\hline Desconhece explicitamente a categoria & 20 \\
Não é importante de maneira geral & 15 \\
Não é importante porque o município é pequeno & 27 \\
Não soube responder & 40 \\
\hline TOTAL & 102 \\
\hline
\end{tabular}

O primeiro ponto a enfatizar é que a maioria das respostas negativas $(58,8 \%)$ enquadra-se nas subcategorias "desconhece explicitamente a categoria" e "não soube responder". Desse modo, os resultados obtidos mostram um grande desconhecimento sobre as possibilidades de contribuição de um cientista social no campo da saúde.

As afirmações taxativas, classificadas nas três primeiras subcategorias, são esperadas em um survey dessa natureza. Entretanto, parece importante distinguir respostas recorrentes em que a negação é mais matizada, fato relacionado diretamente com uma circunstância específica: o tamanho pequeno do município. As respostas localizadas nessa subcategoria dividem-se entre dois tipos: aquelas que apontam para um problema de administração de recursos escassos, proporcionais ao tamanho do município, o que justificaria, segundo os entrevistados, a opção da administração municipal por profissionais mais essenciais na área de saúde (enfermeiros, técnicos de enfermagem, médicos e outros); aquelas que não percebem a importância de um cientista social em um município de pequeno porte, independentemente de problemas com a folha de pagamento.

Dos 427 entrevistados, 325 responderam afirmativamente à questão proposta, o que corresponde a $76 \%$ da amostra. A Tabela 5 apresenta esse dado numérico distribuído nas subcategorias mencionadas. 
TABELA 5

Distribuição das respostas positivas sobre a importância da função do cientista social em subcategorias

\begin{tabular}{lc}
\hline SUbCATEGORIA & FREQUÊNCIA \\
\hline Ajuda & 137 \\
Com funções assemelhadas aos assistentes sociais & 115 \\
Compreensão de problemas complexos & 73 \\
\hline Total & 325 \\
\hline
\end{tabular}

Sob a subcategoria "ajuda”, reunimos respostas que afirmam a presença do cientista social nos termos "ajuda", "soma”, "acrescenta", "é interessante" e "é importante”, sem mais qualificações na justificativa. Sobressai, nesses casos, o desconhecimento que está implícito em afirmações extremamente vagas sobre o significado desse profissional na área da saúde. Há respostas que lhe conferem uma importância aditiva não especificada, relacionada com a ideia de que "tudo é válido", "tudo que vem pra ajudar é importante" ou "tudo que vem pra somar acho interessante”, às vezes associada expressamente à confissão de ignorância sobre sua contribuição específica - como ocorreu, por exemplo, nesta resposta: “Todo profissional vem a agregar, vem somar. Mas não sei realmente o que eles fariam”. Outro gênero de resposta reconhece a importância do cientista social simplesmente pelo valor distintivo da "qualificação", que independe de sua especificidade, a exemplo de respostas como "quanto mais tiver pessoas qualificadas, melhor fica o setor da saúde" ou "acho que é sempre bom ter alguém com uma formação superior".

Outro grupo de respostas positivas foi classificado na subcategoria "com funções assemelhadas aos assistentes sociais”. Nesse caso, a importância dos cientistas sociais estaria vinculada à possibilidade de "esclarecer os funcionários" e desenvolver "treinamento" ou "capacitação". De um lado, trata-se de uma expectativa relativa ao desempenho de funções próprias do setor de recursos humanos, com referências, inclusive, à elaboração de estatutos e planos de carreira; de outro, há uma ênfase na capacidade desse profissional para aprimorar a qualidade da convivência e entendimento entre funcionários e usuários, favorecendo a visibilidade do "lado humano" dessa relação, ou então criando diretamente "técnicas para melhor atendimento" ou programas de "esclarecimento" da população e dos profissionais da saúde. Algumas das respostas dos entrevistados permitem perceber que essas duas ideias estão ancoradas na assimilação do papel do cientista social ao do assistente social.

Por fim, entre as respostas afirmativas sobre a importância do cientista social no SUS, temos a subcategoria "compreensão de problemas complexos". 
Nela reunimos afirmações que assumem como sua atividade própria, que lhe confere sua importância específica, a capacidade de desenvolver uma visão "histórica" ou "social" mais abrangente, conhecimentos relacionados com o "perfil epidemiológico da sociedade" e às questões políticas relativas ao SUS ou, mais especificamente, aos parâmetros participativos previstos na legislação que o regulamenta. Os trechos a seguir são exemplos de respostas que localizamos nessa subcategoria: "Às vezes, na prática, a gente se limita a olhar só o que está posto, não conseguindo olhar a história, não avalia a conjuntura, momento histórico, político do país não faz uma análise mais geral. Se individualiza a situação: 'É um problema de saúde? Passa no médico'”; "Limita a ação não ter um profissional deste [cientista social], na medida em que esse profissional tem uma visão mais ampla da sociedade como um todo e dos fenômenos sociais de uma maneira geral, acho uma pena que não tenha esse profissional"; "Quando a gente fala nos processos de saúde, a gente tem que ver o global. Eles têm conhecimento dessa questão, do perfil epidemiológico da sociedade, até das questões políticas e da participação da comunidade, que é um dos princípios do SUS; podem ajudar assim como parceria com a equipe, auxiliando nessa questão".

Por fim, é importante registrar que alguns profissionais que declaram ser importante a presença do cientista social no quadro de funcionários da saúde desqualificam essa positividade, na justificativa. Isso não se explica apenas pela tendência de o entrevistadeo esconder suas posições e responder - por temor de parecer desinformado ou politicamente incorreto diante do entrevistador - de acordo com o que julga ser a resposta positiva esperada. Há uma "prevenção" de outra natureza, que transparece em algumas falas, um mecanismo de autodefesa que se manifesta em uma atitude evasiva, seja por meio do recurso ao argumento da divisão funcional de competências e, portanto, da suposta incompetência do entrevistado para responder à questão em razão de sua ocupação, seja por meio do recurso à blindagem institucional, como, por exemplo, na afirmação de que "a secretaria não tem autonomia para decidir isso".

Essa atitude de cautela e recuo pode derivar do mesmo contexto gerador de outro dado importante, relativo à recusa dos profissionais de quase 30\% dos municípios a participar da pesquisa - alguns deles recusaram após solicitar que o questionário fosse enviado previamente por e-mail. Não é fácil interpretar essa atitude, mas é possível supor que esteja vinculada a mecanismos institucionais de internalização da crítica ou de autodefesa "corporativa".

Sem antecipar uma interpretação mais profunda desses dados, podemos resumir assim os resultados: 
- A pesquisa aponta para um alto grau de "invisibilidade" do trabalho dos cientistas sociais no campo da saúde, referendada pelo conjunto de informações fornecidas pelos diferentes atores. Essa invisibilidade é reportada tanto pelo desconhecimento confesso sobre as contribuições específicas ou possíveis dos cientistas sociais no campo da saúde quanto pela transposição hermenêutica de referências extraídas de outra categoria profissional (assistente social), ou ainda pela vagueza da maioria das respostas positivas acerca da importância da categoria.

- As percepções sobre o papel do cientista social na área da saúde compreendem algumas possibilidades, como: papel identificável àquele de qualquer função "qualificada" no funcionalismo público, papel idêntico ou similar ao do assistente social e papel específico relativo à compreensão de problemas políticos e sociais de natureza abrangente e complexa.

\section{Os cientistas sociais no sus: percepções intraprofissionais}

Obtivemos o total de 31 referências a cientistas sociais trabalhando em secretarias municipais de saúde do estado de São Paulo, sendo que: quinze constavam nos registros do Ministério da Saúde, por meio do Cadastro Nacional de Estabelecimentos de Saúde (MS-CNES); onze foram identificadas pelo estudo quantitativo e por mensagem eletrônica enviada pelo Conselho de Secretarias Municipais de Saúde (Cosems-SP); cinco foram identificados pela técnica de bola de neve durante as entrevistas. Do total mencionado, entrevistamos catorze profissionais, pois alguns deles recusaram-se a participar da pesquisa, outros foram impedidos por normas técnicas de seus municípios e outros, ainda, não foram encontrados.

$\mathrm{Na}$ Tabela 6, são apresentadas as características demográficas dos participantes e a identificação com que nos referiremos a cada um deles. Trata-se de um grupo quase exclusivamente feminino, a maioria na faixa de 45 anos, mas variando de 26 a 64 anos, com uma variação de renda entre dois e treze salários mínimos. Há um predomínio de mulheres casadas e católicas.

A Tabela 7 apresenta formação, ocupação atual e anterior, local de trabalho, carga horária semanal e função atual. Três entrevistados podem ser considerados trabalhadores da saúde que estudaram ciências sociais, pois tinham formação anterior que lhes permitia inserção no campo da saúde e graduaram-se nesse curso já na qualidade de profissionais atuantes em saúde. Os outros onze entrevistados são cientistas sociais trabalhando na saúde, ou seja, com inserção no campo da saúde após a conclusão do curso de graduação. A carga 
horária semanal é de período integral para onze dos catorze entrevistados, o que permite considerar que esta é a ocupação principal desses profissionais. Onze participantes fizeram estudos de pós-graduação latu ou stricto sensu. Um fez mestrado e doutorado na área de saúde do trabalhador e os outros dez fizeram especialização em diferentes campos, como saúde pública, gestão em saúde pública, gerência urbana, sociologia política, Estado e sociedade, saúde pública e recursos humanos e educação e saúde pública.

TABELA 6

Características demográficas dos participantes

\begin{tabular}{|c|c|c|c|c|c|}
\hline Nome & SEXo & IDADE & ESTADO CIVIL & RELIGião & RENDA $^{*}$ \\
\hline CCRM & $\mathrm{F}$ & 47 & Casada & Sem religião & 3 \\
\hline MAR & $\mathrm{F}$ & 59 & Solteira & Católica & 9 \\
\hline МАBCT & $\mathrm{F}$ & 57 & Casada & Sem religião & 13 \\
\hline $\mathrm{IH}$ & F & 64 & Viúva & Acredito em Deus & 5 \\
\hline SAS & M & 28 & Solteiro & Católica & 4 \\
\hline $\mathrm{JCB}$ & $\mathrm{F}$ & 26 & Solteira & Agnóstica & 6 \\
\hline MF & $\mathrm{F}$ & 48 & Casada & Evangélica & 4 \\
\hline IASG & $\mathrm{F}$ & 45 & Casada & Católica & 9 \\
\hline MCML & $\mathrm{F}$ & 61 & Viúva & Católica & 5 \\
\hline FCS & $\mathrm{F}$ & 26 & Solteira & Protestante & 2 \\
\hline MAS & $\mathrm{F}$ & 48 & Solteira & Evangélica & 3 \\
\hline SEM & $\mathrm{F}$ & 51 & Divorciada & Católica & 10 \\
\hline RASV & $\mathrm{F}$ & 33 & Casada & Católica & 4 \\
\hline $\mathrm{FF}$ & $\mathrm{F}$ & 49 & Casada & Espírita & 6 \\
\hline
\end{tabular}

*Em salários mínimos $(1=\mathrm{R} \$ 565,00)$. 
TABELA 7

Dados ocupacionais dos participantes

\begin{tabular}{|c|c|c|c|c|c|c|}
\hline Nome & $\begin{array}{c}\text { FORMAÇÃO/ } \\
\text { TEMPO EM ANOS }\end{array}$ & $\begin{array}{l}\text { OCUPAÇÃO } \\
\text { ATUAL }\end{array}$ & $\begin{array}{l}\text { OCUPAÇÃO } \\
\text { ANTERIOR }\end{array}$ & $\begin{array}{l}\text { LOCAL DE } \\
\text { TRABALHO }\end{array}$ & $\begin{array}{c}\text { HORAS } \\
\text { SEMANAIS }\end{array}$ & FUNÇÃO \\
\hline CCRM & Ciências sociais/10 & Socióloga & $\begin{array}{l}\text { Professora Assisten- } \\
\text { te técnica }\end{array}$ & Cerest & 40 & $\begin{array}{l}\text { Socióloga do } \\
\text { trabalho }\end{array}$ \\
\hline MAR & $\begin{array}{l}\text { Ciências sociais e } \\
\text { pedagogia/35 }\end{array}$ & $\begin{array}{l}\text { Coordenação do } \\
\text { Cerest }\end{array}$ & Não teve & SMS & 40 & $\begin{array}{l}\text { Coordenação do } \\
\text { Cerest }\end{array}$ \\
\hline MABCT & $\mathrm{CS} / 35$ & $\begin{array}{l}\text { Socióloga no } \\
\text { Cerest }\end{array}$ & $\begin{array}{l}\text { Socióloga do } \\
\text { serviço de medicina } \\
\text { do trabalho de um } \\
\text { hospital }\end{array}$ & Cerest & 28 & $\begin{array}{l}\text { Supervisora de } \\
\text { equipe de reabilita- } \\
\text { ção profissional }\end{array}$ \\
\hline $\mathrm{IH}$ & $\begin{array}{l}\text { Bacharel em ciências } \\
\text { sociais e ciências } \\
\text { políticas/- }\end{array}$ & $\begin{array}{l}\text { Coordenadora do } \\
\text { Centro Integrado } \\
\text { Saúde-Educação } \\
\text { Terceira Idade }\end{array}$ & Socióloga & $\begin{array}{l}\text { Centro Integrado } \\
\text { Saúde-Educação } \\
\text { Terceira Idade }\end{array}$ & 40 & $\begin{array}{l}\text { Coordenadora do } \\
\text { Centro Integrado } \\
\text { Saúde-Educação } \\
\text { Terceira Idade }\end{array}$ \\
\hline SAS & $\begin{array}{l}\text { Licenciatura em } \\
\text { ciências sociais e } \\
\text { bacharelado em } \\
\text { sociologia/4 }\end{array}$ & $\begin{array}{l}\text { Gestor municipal } \\
\text { de saúde }\end{array}$ & $\begin{array}{l}\text { Agente comunitá- } \\
\text { rio de saúde }\end{array}$ & SMS & 40 & Secretário de Saúde \\
\hline $\mathrm{JCB}$ & Ciências sociais/- & $\begin{array}{l}\text { Coordenadora do } \\
\text { programa de DST- } \\
\text {-Aids }\end{array}$ & $\begin{array}{l}\text { Assistente Técnica } \\
\text { do programa de } \\
\text { DST-Aids }\end{array}$ & $\begin{array}{l}\text { Programa DST- } \\
\text {-Aids }\end{array}$ & 40 & $\begin{array}{l}\text { Coordenadora do } \\
\text { programa de DST- } \\
\text {-Aids }\end{array}$ \\
\hline MF & Sociologia/12 & $\begin{array}{l}\text { Supervisora técnica } \\
\text { do programa DST- } \\
\text {-Aids }\end{array}$ & Assessora legislativa & SMS & 40 & $\begin{array}{l}\text { Planejamento de } \\
\text { projetos e pesquisas }\end{array}$ \\
\hline IASG & Ciências sociais/19 & $\begin{array}{l}\text { Assessora Especial } \\
\text { de gabinete do } \\
\text { secretário de Saúde }\end{array}$ & $\begin{array}{l}\text { Agente adminis- } \\
\text { trativo }\end{array}$ & SMS & 40 & $\begin{array}{l}\text { Assessora especial } \\
\text { de gabinete }\end{array}$ \\
\hline MCML & Ciências sociais/- & $\begin{array}{l}\text { Assessora na Secre- } \\
\text { taria Municipal de } \\
\text { Saúde }\end{array}$ & $\begin{array}{l}\text { Assistente de dire- } \\
\text { ção na assessoria de } \\
\text { Estado da saúde }\end{array}$ & SMS & 40 & Assessora na SMS \\
\hline MAS & Ciências sociais/- & Técnica superior & $\begin{array}{l}\text { Área Adminis- } \\
\text { trativa }\end{array}$ & $\begin{array}{l}\text { Vigilância Epide- } \\
\text { miológica }\end{array}$ & 20 & $\begin{array}{l}\text { Informação, educa- } \\
\text { ção e comunicação }\end{array}$ \\
\hline SEM & Sociologia/25 & $\begin{array}{l}\text { Socióloga supervi- } \\
\text { sora de curso }\end{array}$ & $\begin{array}{l}\text { Socióloga em dife- } \\
\text { rentes secretarias } \\
\text { municipais }\end{array}$ & $\begin{array}{l}\text { Setor de informa- } \\
\text { ção de epidemio- } \\
\text { logia na SMS }\end{array}$ & 40 & $\begin{array}{l}\text { Supervisora de } \\
\text { curso }\end{array}$ \\
\hline $\mathrm{FCS}$ & Ciências sociais/3 & $\begin{array}{l}\text { Agente adminis- } \\
\text { trativa }\end{array}$ & Não teve & SMS & 40 & $\begin{array}{l}\text { Agente adminis- } \\
\text { trativa }\end{array}$ \\
\hline RASV & Ciências sociais/7 & $\begin{array}{l}\text { Agente adminis- } \\
\text { trativa }\end{array}$ & Recepcionista & $\begin{array}{l}\text { Centro Municipal } \\
\text { de Saúde }\end{array}$ & 20 & $\begin{array}{l}\text { Agente adminis- } \\
\text { trativa }\end{array}$ \\
\hline $\mathrm{FF}$ & Ciências sociais/- & $\begin{array}{l}\text { Técnica de enfer- } \\
\text { magem }\end{array}$ & $\begin{array}{l}\text { Técnica de enfer- } \\
\text { magem }\end{array}$ & $\begin{array}{l}\text { Unidade de Saúde } \\
\text { da Família }\end{array}$ & 40 & $\begin{array}{l}\text { Técnica de enferma- } \\
\text { gem e vacinadora }\end{array}$ \\
\hline
\end{tabular}

Cerest - Centro de Referência em Saúde do Trabalhador.

SMS - Secretaria Municipal de Saúde. 
Uma vez identificadas, de forma direta, suas características demográficas e ocupacionais, foi solicitado aos entrevistados que respondessem como entraram na área da saúde. As respostas foram diferentes, porém, com um padrão verificado em todos os casos: trabalhar como cientista social na área da saúde não foi uma opção planejada ou um projeto profissional desejado desde o início da vida produtiva e aconteceu por acaso.

Ainda que o trabalho no campo da saúde não tenha sido uma opção construída no início da carreira, procuramos aprofundar um pouco mais o contexto dessa ocupação ao questionar como os entrevistados se sentem trabalhando na área da saúde.

Os profissionais que atuam no Centro de Referência em Saúde do Trabalhador (Cerest) - CCRM (socióloga do trabalho), MAR (coordenadora) e MABCT (supervisora da equipe de reabilitação profissional) - expõem uma relação bastante positiva com o campo de atuação. CCRM relata que se sente “contribuindo bastante devido ao interesse e à formação", MAR diz estar "cada vez mais apaixonada" е MABCT afirma ter "uma afinidade muito grande com essa área, apesar das dificuldades". Aparentemente, a possibilidade de construção de uma identidade positiva no campo da saúde por esses profissionais está relacionada com a intersecção com uma subárea acadêmica específica das ciências sociais, a sociologia do trabalho, que, de acordo com CCRM, "é uma área que trabalha muito com a questão da prevenção e, particularmente, com a sociologia do trabalho, o processo de trabalho, as relações do trabalho. É uma área pela qual sempre me interessei muito, então me sinto contribuindo bastante devido ao interesse à minha formação".

O interesse de MAR não se expressa apenas pela referida "paixão", mas também pela permanência do interesse investigativo em seu campo de atuação, o que aponta para a percepção de um terreno de possibilidades ainda não esgotadas para sua atividade: "É uma coisa que eu quero continuar, que eu quero investigar mais, que eu quero estudar mais, sabe?”. No caso de MABCT, há outro fator, diferente da "afinidade" com a área, que favorece sua identificação com o campo de atuação: o trabalho no funcionalismo público, ou melhor, a rejeição ao trabalho na iniciativa privada. Em suas palavras: "não me vejo trabalhando em nenhum outro lugar. Eu não me sentiria capaz de trabalhar na área privada e tenho uma afinidade muito grande com essa área, apesar de todas as dificuldades". A entrevista, infelizmente, não captou o significado das "dificuldades" mencionadas.

Há outros profissionais que expõem um sentido positivo em seu trabalho no campo da saúde, embora sejam casos em que é difícil apreender o sentido 
da construção de tal identificação profissional positiva. IH, coordenadora do Centro Integrado Saúde-Educação da Terceira Idade, limita-se a exprimir sua "realização", sem quaisquer glosas: "Eu me sinto uma pessoa realizada na área da saúde". Outra profissional que se diz "extremamente realizada” é FCS, agente administrativa, um dos casos, em nossa pesquisa, de trabalhadores da saúde que posteriormente estudaram ciências sociais. Ela aponta para a importância da presença de cientistas sociais no campo da saúde, mas não explica se e como essa importância se repõe em seu cargo: "Extremamente realizada. Eu estou até num dilema, prestei outro concurso e estou pensando... Eu estou realizada porque é muito importante a questão do cientista social na saúde”.

Há também o relato de SAS, um agente comunitário de saúde que se tornou secretário de saúde. Trata-se de um caso curioso, em que o desejo manifesto de "construir carreira dentro da área de saúde pública" se inscreve em uma estratégia, contraditória, ao menos na aparência. Com efeito, ele pretende abandonar o cargo de secretário, posto máximo dentro da hierarquia da saúde pública municipal, para assumir, como concursado, o de professor de sociologia no ensino médio da rede estadual, mas com o intuito de no futuro voltar para a saúde pública como "profissional de carreira". Em sua fala, SAS afirma a contribuição positiva de sua formação em ciências sociais para sua atuação: "Olha, eu acho que a minha faculdade, a minha formação, deu um know-how, um saber fazer e um saber trabalhar dentro da saúde pública”.

Um caso interessante entre os entrevistados que conferem sentido positivo à inserção profissional no SUS é o de IASG, que trabalha como assessora especial do gabinete do secretário da Saúde. Ela afirma gostar muito da área e relembra o momento de seu ingresso, fortemente marcado por um contexto social e político específico de construção de um novo cenário institucional, com a Constituição de 1988 e a instituição do SUS. A vivência de um contexto de mudança, de transição, e o sentimento de participação nesse processo, que inseria a saúde em um "outro panorama, que me seduziu um pouco", parecem ser os fatores que alimentam o sentimento positivo de sua presença na saúde:

É uma área que gosto muito. Depois que fiz a faculdade tive a opção de fazer outro caminho, poderia ter ido pra outras secretarias, mas gostei da área da saúde. Eu me sentia começando com ela e, como entrei em 1987, 1988, a gente aprovou a Constituição, e comecei a ver que a saúde estava em um outro panorama, que me seduziu um pouco. Daí, logo em seguida, em 1990, quando eu estava entrando na faculdade, saiu a Lei Orgânica da Saúde, regulamentaram a Constituição, aí essa coisa foi acendendo e - quando você começa a trabalhar na saúde, principalmente, no interior, em cidade 
pequena, começa a ver a necessidade das pessoas - foi uma coisa que foi me absorvendo e, quando vi, já estava dentro, e gosto disso.

As duas profissionais, MF e JCB, que atuam no Programa DST-Aids referem-se à importância da presença de cientistas sociais no campo da saúde, mas com um tom diferente dos entrevistados já mencionados. MF não responde diretamente à pergunta sobre como se sente trabalhando na área da saúde. Ela expõe, indiretamente, a importância do cientista social no SUS apenas no sentido de possibilidades e potencialidades, enquanto lamenta a ausência desse profissional em alguns programas específicos do SUS, como o Programa de Agente Comunitário da Saúde, deixando, assim, alguns indícios para entender seu próprio "lugar" nesse sistema, talvez de potencialidades subaproveitadas ou desativadas em sua atuação profissional. MF entrevê possibilidades para o cientista social no campo da saúde, relacionadas com a especificidade de "uma análise mais social” dos fatores interagentes no processo de saúde-doença-cuidado e na administração de um sistema com grande "diversidade cultural e social”.

Eu acho que é um grande campo para o cientista social, principalmente pelo SUS, devido à sua proposta de equidade... Então seria um amplo sistema, tanto pelo acesso quanto pela diversidade cultural e social das pessoas, pela diversidade de administrar o SUS diante da ocorrência das doenças e suas características, epidemiologia, planejamento e resultados. Eu lamento que no Programa de Agente Comunitário da Saúde não tenha o cientista social, pois lida diretamente com a população e muitos dados, e ele teria uma análise mais social.

Como MF, JCB refere-se a um campo "muito rico" para a atuação do cientista social, mas expõe mais abertamente a dissonância entre a importância desse profissional e o reconhecimento social dessa importância. Antecipa, inclusive, uma hipótese interpretativa sobre esse fato, chamando a atenção para a concentração desses profissionais na área acadêmica, em detrimento de sua presença mais significativa em outro setor da realidade, que ela designa de "prática”. Eis sua resposta: "Por a gente não ter muitos sociólogos na pasta, acho que muitas pessoas não dão a devida importância para a nossa interferência na realidade, até porque muitos cientistas sociais estão na área acadêmica, não na prática. Mas, para mim, é muito rico, porque eu acho que a saúde pública é tão importante quanto a educação, a habitação".

Embora com falas diversas, MAS e SEM, ambas alocadas em setores vinculados à informação e à educação em epidemiologia, referem-se a formas de 
desconforto e "estranhamento" em seu campo de atuação. Em um sentido próximo ao do unhomed ("estranho no lar"), na elaboração de Bhabha (2003), MAS afirma sentir-se, às vezes, como "um peixe fora d'água". Ela fala da dificuldade de entendimento, de comunicação e de reconhecimento recíproco entre o cientista social e outros profissionais em seu campo de atuação; mais especificamente, menciona a dificuldade dos profissionais que operam por meio de um "modelo" biomédico de aceitar e compreender sua presença e contribuição específica no campo da saúde: "Às vezes, você vê coisas que ninguém está vendo". Outro ponto que favorece o "desentendimento" é a indeterminação do próprio papel do cientista social no campo da saúde. A delimitação ou, em sentido positivo, a determinação desse papel depende, como diz MAS, da "postura do profissional”. A resposta de MAS é uma das mais interessantes da pesquisa:

Às vezes, [me sinto] um peixe fora d'água. Às vezes, você vê coisas que ninguém está vendo. Aí eles começam a focalizar muito a área da doença, aqueles órgãos, aqueles vírus. Mas, não só isso, existem outras coisas... Mas [me sinto] um peixe fora d'água. O pessoal, desde que eu cheguei aqui, me recebeu superbem, primeiro achou estranho, mas também não entendia muito bem qual era minha função, meu papel. Com o tempo a gente vai conquistando. Depende muito da postura do profissional, né? A gente tem que pensar muito na nossa postura, né? E a gente vai completando os espaços, delimitando: "Olha, essa não é minha área. Eu não entendo, eu não entendo de saúde física, de doença. E não quero. Muito obrigada. Não é a minha especialidade. Não é a minha. Não quero isso. Minha área é outra. É com isso que eu vou contribuir".

SEM, uma servidora de carreira, com três décadas na prefeitura e experiências em diferentes secretarias do município, fala de um sentimento de desgaste. Inicialmente, ela tende a interpretar esse sentimento como relativo ao tempo de trabalho e ao desejo, ainda não realizável, de aposentadoria. Inquirida, no entanto, sobre a possibilidade de haver "uma relação entre estar trabalhando na área de saúde e esse sentimento de desgaste", ela atribui seu "desgaste" a problemas relacionados com a própria "instituição" e à ausência de "um objetivo maior" no funcionalismo público, mas não fica claro se o que produziu o "desgaste" é o modo de funcionamento e a perspectiva do funcionalismo público em geral ou da Secretaria de Saúde e de seu contexto imediato de trabalho em particular. SEM não constrói um sentido de identidade com sua ocupação atual com base em um momento histórico pregresso - como IASG - ou em potencialidades virtuais - como MF. No seu relato, há somente 
o sentimento do "desgaste" provocado pela experiência profissional em uma instituição que se move como se tivesse "vida própria", mas que é incapaz de construir e afirmar um "objetivo maior".

Sentimentos de "desgaste" e "falta de identidade" também atravessam as falas de RASV e FF, que se enquadram na categoria de profissionais da saúde que estudaram ciências sociais. RASV trabalha como agente administrativo, mas, diferente de FCS, não se identifica com a função que desempenha: "Olha, o trabalho que eu faço não tem muito a ver com a minha profissão". Seu desconforto é tal que não sabe dizer como se sente trabalhando na área da saúde: "Nessa área, como que eu me sinto? Não sei te dizer, é meio complicado [risos]... não sei te dizer."

FF, técnica de enfermagem, acha o trabalho no campo da saúde "apaixonante”, mas também reporta uma sensação de "desgaste”. Ela identifica esse sentimento com o "sucateamento" vivenciado pelos trabalhadores de sua categoria profissional: "[O trabalho é] apaixonante, mas [me sinto] desgastada. Eu faço o que eu gosto, gosto da área. Continuei por escolha, mas vejo que o sucateamento que tem hoje faz com que o profissional fique extremamente desgastado, além do normal".

Outra entrevistada, MCML, aponta ainda para um problema de "precariedade" e afirma sentir tristeza por "sair agora": "Eu vou sair agora, mas o momento que estou vivendo, todas as precariedades que tenho, enfim... Estou até meio triste, mas preciso sair”. Não se sabe se sua saída está relacionada com uma aposentadoria ou com o deslocamento de um cargo nomeado. Não sabemos também se as "precariedades" a que ela se refere estão no âmbito da vida privada ou no universo de seu trabalho.

Apesar da diversidade apresentada, gostaríamos de enfatizar alguns elementos importantes da inserção dos cientistas sociais no campo da saúde: a) o trabalho no campo da saúde não foi uma opção planejada ou um projeto profissional desejado desde o início da vida produtiva e aconteceu por acaso; b) a maioria dos entrevistados expõe um sentido positivo de sua atuação no campo da saúde, mas esse sentido não é especificado, apenas traduzido em termos de "realização" ou "paixão" pelo campo, ou ainda na forma de um reconhecimento vago da importância da presença desse profissional na área da saúde; c) nos casos em que esse sentido positivo é mais especificado, emergem possibilidades bastante distintas, como a identificação em razão da relação do setor de atuação (saúde do trabalhador) com uma área específica de interesse das ciências sociais (sociologia do trabalho), a identificação com as potencialidades virtuais de atuação dentro do campo em razão dos parâmetros de regulação do 
SUS, a identificação com um momento histórico específico de configuração do campo da saúde pela institucionalização do SUS ou a identificação com a possibilidade de introduzir uma visão diferenciada, "mais social", do processo saúde-doença-cuidado e da administração do SUS; d) malgrado a predominância dessa interpretação positiva da própria inserção no campo, é importante apontar dificuldades nesse processo, como a não identificação com a função desempenhada em virtude da distância com a área de formação, o "desgaste" em razão da precariedade material da instituição, o "desgaste” em razão do modus operandi da instituição ou, mais diretamente, da ausência de projeto institucional construído e assumido pelo funcionalismo público na área da saúde, o não reconhecimento interprofissional e a dificuldade de afirmação do papel diferenciado do cientista social no campo da saúde.

\section{Considerações finais}

Apesar de contar com uma tradição de cerca de meio século, é pequeno o contingente de cientistas sociais no campo da saúde. Esse fenômeno é atestado pelo número de registros do MS-CNES, que disponibiliza informações das condições de infraestrutura e funcionamento do SUS nos âmbitos federal, estadual e municipal. Em consulta realizada em maio de 2014, constavam registrados apenas 55 sociólogos e nenhum antropólogo ou cientista político entre os cerca de 2 milhões de profissionais de saúde no SUS (MS-CNES, 2014; WHO, 2013).

Essa desproporção numérica é apenas o sintoma de um processo mais amplo que, seguindo certa tradição, chamaremos de "colonização" (Pathak, 2013) do campo da saúde. Tal "colonização” tem algumas características importantes, assinaladas de modo breve neste artigo. Em primeiro lugar, ela se desenvolve no contexto de dominância, em escala social ampla, de uma "cultura de especialistas”, que concentra importantes processos de decisão relativos às esferas individual e coletiva da vida, nas mãos daqueles profissionais, legitimados em função do caráter supostamente "imparcial”, "objetivo” e, por isso, confiável de suas competências e conhecimentos. Em segundo lugar, situa-se na "cultura protocolar" específica da administração estatal, a qual impõe determinadas condições para interação dos atores do campo da saúde. Por fim, remete a um determinado padrão de "racionalidade" ético-terapêutico baseado na postulação da superioridade das competências biomédicas, na centralidade do médico e na "geografização" (Laplantine, 1991) da doença, reificada e tratada topologicamente em termos biomédicos. 
Mais do que no número de cientistas sociais no SUS, essa "colonização" se evidencia na "exclusão" desses profissionais do quadro de profissões da Classificação Brasileira de Ocupações (СBO) (MTE, 2011) do campo da saúde no Brasil, oficialmente composto de catorze áreas - biologia, biomedicina, enfermagem, farmácia, fisioterapia, fonoaudiologia, medicina, nutrição, odontologia, psicologia, química, veterinária, terapia ocupacional e serviço social - e outras duas correlacionadas - saúde coletiva e economia (Machado, 1995; Giradi, 2000; Teixeira, 2004; Assunção et al., 2007; CNS, 2011). Certamente, existir e não pertencer potencializa as expressões de dominação, acentuando as contradições entre aquilo que os cientistas sociais e seus chefes imediatos, geralmente profissionais de saúde, veem como contribuição para o campo da saúde.

No entanto, a fim de evitar uma análise unilateral, é necessário observar que, por razões mais internas da constituição do campo das ciências sociais, como seu caráter fortemente "academicizante" ou suas hierarquizações particulares, algumas dificuldades para a inserção significativa dos cientistas sociais na área da saúde são produzidas em seu interior (Boneli, 1993; Bastos, 2002; Braga, 2009; 2011). Algo importante a registrar é que os cursos de graduação em ciências sociais, em geral, não garantem ou garantem pouca formação para o trabalho com questões da saúde. Trata-se de uma atitude que reflete e reproduz a desvalorização do trabalho no âmbito da saúde, contribuindo para a manutenção da situação colonizada dos cientistas sociais (Schwartzman, 2011).

Diante desse contexto, começamos a compreender o "lugar" do cientista social que ingressa no campo da saúde e, mais especificamente, atua na gestão do SUS. (1) Trata-se de um campo colonizado por uma forma de "racionalidade" que não suporta a ambivalência de padróes concorrentes que desafiem a confiabilidade, a legitimidade ou a naturalidade dessa racionalidade plasmadora dos modos de sociabilidade instituídos. (2) É um campo em que a profissão de cientista social não é oficialmente reconhecida e, em geral, ocupa cargos não definidos de modo disciplinar - os quais podem ocupar justamente em razão da natureza indiferenciada da qualificação requerida, o que dificulta delinear uma identidade profissional baseada em sua formação. (3) Em virtude das próprias dificuldades de inserção no campo, não foi gerada uma cultura profissional que defina parâmetros cognitivos e práticos para a atuação do cientista social no âmbito do SUs, lembrando que, como observa Abbott (1988), as profissões desenvolvem-se não somente nas relações intraprofissionais, mas também nas relações interprofissionais, ou seja, nos processos de competição, conflito e cooperação com outros grupos profissionais. (4) O cientista social 
deve construir parâmetros em suas relações intra e interprofissionais, sem que sua formação acadêmica o prepare de maneira direta para uma reflexão mais profunda sobre o campo da saúde e sobre suas possibilidades de atuação nesse campo. (5) Nesse processo complicado e conflituoso, o cientista social que ingressa no campo da saúde não conta com uma linha de trincheira na retaguarda, quer dizer, em seu próprio campo de origem, pois, em grande medida, sua atuação na saúde é desvalorizada ou simplesmente ignorada pelo campo das ciências sociais. É nesse incômodo "lugar" que ele deve encontrar espaço para seu "corpo estranho", expondo-se como "indivíduos que cruzam o limite entre grupos" e que não se sentem "seguros de pertencer ao grupo no qual estão entrando nem também àquele de que estão saindo" (Bauman, 1999, p. 130).

Não é somente o cientista social que tem de encontrar um lugar para seu "corpo estranho", mas também os outros profissionais que interagem com ele na área da saúde. Vale lembrar que, de acordo com Bauman (1999), o "estranho" escapa à onipotência da razão ordenadora, quebra a clareza cognitiva, classificatória, gerando problemas hermenêuticos que desbordam da esfera cognitiva para o território das certezas comportamentais. Esses problemas hermenêuticos precisam ser contornados ou suprimidos, em benefício da reposição das certezas cognitivas e comportamentais solapadas e, assim, da conservação da visão e da estrutura da organização social sedimentadas.

Cognitivamente, o estranho pode ser deglutido na forma da negação de sua estranheza. Pudemos captar nas entrevistas com profissionais da gestão da saúde dois expedientes dessa estratégia. O primeiro diz respeito à alienação da "estranheza" do cientista social no campo da saúde, por meio de sua interpretação como mais uma função "qualificada" de natureza especializada, a qual, pela suposta transcendência das competências específicas diante do não especialista , não pode ser completamente compreendida, mas apenas reverenciada, uma vez que o poder anônimo da "inteligência pública" a reconheceu como digna de figurar entre seus quadros. Assim, a estranheza é isolada pela atitude reverencial, que permite ignorá-la no curso da rotina cotidiana. $O$ segundo expediente se dá com a alienação da "estranheza" do cientista social no campo da saúde pela transposição hermenêutica de referências extraídas de outra categoria profissional - designadamente, do assistente social.

Na prática, no caso daqueles que precisam, de fato, interagir com os cientistas sociais, essas saídas não constituem uma solução. Se não se pretende questionar os limites constitutivos da forma de "racionalidade" dominante no campo, a estratégia mais óbvia, dentro da linha de menor resistência, é o "convite à assimilação", que tem como contraface a ameaça de eliminação, 
exoneração ou autoexoneração, ou ainda de eliminação “social”, invisibilidade e não efetividade de sua atuação.

Como afirma Bauman (1999, p. 114), apesar da extensão do campo de referência do termo, "literalmente, assimilação significa tornar semelhante". Em nossa pesquisa, a assimilação opera por meio de um "convite", na forma de pressão ou constrangimento, a aderir às expressões do modelo biomédico vigente, reconhecendo não apenas a sua superioridade, mas também as hierarquias profissionais existentes no campo da saúde.

A resposta a esse convite à assimilação compreende duas possibilidades mais evidentes. A primeira é aceitar o convite e abandonar toda pretensão a questionar a validade dos parâmetros definidores do campo: limitar seu âmbito de atuação a um modo de atuação subsidiário, assumir, em parte, os termos de referência e a linguagem própria da "racionalidade" dominante, fazendo com que suas potencialidades de cientista social sejam alijadas para um território virtual e com que o próprio profissional desenvolva uma existência invisível uma "arte secreta da invisibilidade" - enquanto constrói uma "identificação colonial, com a cisão do sujeito em seu lugar histórico de enunciação” (Bhabha, 2003, p. 79). Compreende-se, assim, que para muitos cientistas sociais, como MF e IASG, a única maneira de explicar o sentido positivo de sua presença no campo da saúde ocorre por meio da alusão a potencialidades virtuais ou a um momento histórico de transição institucional, de redução relativa da força e da rigidez de seus parâmetros protocolares definidores e, portanto, de ampliação relativa das possibilidades desconstrutivas e construtivas do cientista social. A segunda possibilidade é a de que o cientista social se recuse a ser "assimilado" e assuma o ônus de uma luta isolada, intrinsecamente individual, sem qualquer retaguarda, para sustentar a vitalidade dos padrões distintos de compreensão e atuação no campo da saúde. Alguns dos aspectos desse ônus são expressos por MAS, quando se refere ao sentir-se "um peixe fora d'água", ao perder toda espontaneidade comportamental e assumir, como conduta, uma reflexividade sem descanso sobre a "própria postura", em um esforço constante de "delimitação".

Claro que os casos concretos, por uma razão de ordem mais geral, são muito mais matizados e fluidos do que as situações representadas nessas duas opções. Isso porque o processo interacional é pleno de retroalimentações que reorientam constantemente os sentidos das escolhas e estratégias individuais e coletivas. Assim, diferentes atores, objetos e ambientes estimulam e deixam de estimular, ativam e reprimem ações individuais e coletivas, em um contexto de impactos múltiplos recíprocos. Não se pode, assim, considerar as posições dos entrevistados nas duas partes da pesquisa estanques, representando perspectivas 
completamente cristalizadas. Além disso, os contextos em que ingressam os cientistas sociais podem ser e são, de fato, muito diversos. Como demonstra nossa pesquisa, há repercussões diversas entre os sociólogos que conseguem estabelecer comunicação de uma área específica das ciências sociais com um setor específico da saúde, entre aqueles que se vinculam a áreas como a epidemiologia, em que o conflito potencial com o "modelo" biomédico é maior, entre os profissionais do campo da saúde que estudaram ciências sociais e permanecem em seus antigos postos, com maior ou menor possibilidade de reinventarem seu modo de atuação e entre os cientistas sociais que ingressam em equipes multidisciplinares de setores ou programas específicos no campo da saúde.

É fundamental observar que aqueles que responderam o questionário são profissionais que ocupam posições diferenciadas na escala de poder dos municípios, e alguns deles têm acesso à informação e influência em decisões e projetos. Essa diversidade é importante para assegurar a representatividade da amostra e é um ponto forte desta pesquisa. Também é preciso reconhecer que não é possível apreender de uma pesquisa como esta todos os elementos condicionais importantes para entender as respostas, particularmente relacionados com situações específicas de trabalho, que certamente ajudam a constituir o lugar de discurso dos entrevistados.

Vale observar que os pontos discutidos neste artigo procuram compreender dificuldades específicas do ingresso do cientista social no campo da saúde e, mais especificamente, no sUS. Isso não quer dizer que não haja dificuldades análogas, embora não idênticas, para o estabelecimento de uma identidade profissional fora do campo da saúde, mesmo porque é possível identificar certa "homologia" entre as formas de "racionalidade" que dominam o momento prático-institucional em distintos campos de atuação, considerando: a transversalidade da ideologia racionalista; a "onipotência virtual” e a neutralização axiológica da "razão técnica"; e a sobredeterminação dos limites e das possibilidades de diferentes campos por processos sociais, econômicos, políticos e culturais mais abrangentes. Não obstante, essas semelhanças não nos devem impedir de considerar questões específicas à inserção do cientista social no campo da saúde, como a dominância da "racionalidade" biomédica no campo oficial da saúde e a desvalorização do tema da saúde na hierarquia acadêmica das áreas de ciências sociais.

Por fim, apontamos para a necessidade de se construir linhas de investigação que problematizem a atuação profissional dos cientistas sociais no campo da saúde. O desafio é identificar bases de controle cognitivo e social das suas atividades, compreendendo que tal processo exige não somente reconhecimento 
social ou legitimação de uma estrutura cognitiva (Diniz, 2001; Freidson, 2009), mas também a abertura ou a expansão dos limites do próprio campo por meio do enfrentamento da estrutura de "colonização" estabelecida, o que envolve reconhecer e analisar o próprio papel do "colonizado" como copartícipe da produção e reprodução dessa estrutura. Esse desafio exige que o cientista social consiga superar seu "isolamento" tanto no campo da saúde como em outros em que ele esteja à margem, não apenas criando fóruns estaduais e nacionais no campo da saúde, por exemplo, mas estabelecendo uma rede de alianças com os diversos atores profissionais e não profissionais interessados em questionar a validade dos parâmetros estruturadores de distintos campos cognitivos e práticos. É necessário, portanto, elaborar estratégias relacionadas com o que Sennett (2012) - na esteira de Robert Putnan - chama de "interações sociais de ligação", que são voltadas para dentro e tendem a reforçar identidades exclusivas e grupos homogêneos, e, igualmente, ao que ele chama de "relacionamentos sociais de transposição", que são voltados para fora e incluem pessoas de diversas origens sociais.

\section{Referências bibliográficas}

Аввотт, Andrew. (1988), The system of professions: an essay on the division of expert labor. Chicago, University of Chicago Press.

Assunção, Ada Ávila; Belisário, Soraya Almeida; Campos, Francisco Eduardo \& D’Ávila, Luciana Souza. (2007), "Recursos humanos e trabalho em saúde: os desafios para uma agenda de pesquisa”. Cadernos de Saúde Pública, 23 (2): 193-201.

BASTOS, Elide Rugai. (2002), “Ciências sociais e trabalho intelectual”. Tempo Social, 2 (14): 209-212.

Bauman, Zigmund. (1999), Modernidade e ambivalência. Rio de Janeiro, Jorge Zahar. BHAвнA, Homi K. (2003), O local da cultura. Belo Horizonte, Editora da UfMG.

Bonelli, Maria Glória. (1993), Identidade profissional e mercado de trabalho dos cientistas sociais: as ciências sociais no sistema das profissöes. Tese de doutorado, Campinas, IFCH-Unicamp.

BRAGA, Eugênio Carlos Ferreira. (2009), Composição e posiçôes ocupacionais para outra sociologia dos cientistas sociais. Tese de doutorado. Campinas, IFCH-Unicamp.

. (2011), "Novos elementos para uma sociologia dos cientistas sociais: a situação ocupacional dos egressos”. Revista Brasileira de Ciências Sociais, 76 (26): 103-112.

CANeSQui, Ana Maria. (2008), "As ciências sociais e humanas em saúde na Associação Brasileira de Pós-graduação em Saúde Coletiva”. Physis, 2 (18): 215-250. 
(1995), Dilemas e desafios das ciências sociais na saúde coletiva. São Paulo, Hucitec. . (1998), "Ciências sociais e saúde: três décadas de ensino e pesquisa no Brasil". Ciência e Saúde Coletiva, 2 (3): 131-168.

Cockerham, William C. (2005), "Medical sociology at the millennium". In: SCAMBLER, G (org.). Medical sociology: major themes in health and social welfare. Londres, Routledge.

CONSElHo NACiONAL DE SAÚDE - CNS. (1998), Resolução n. 287 de 8 de outubro de 1998 (Relacionar as seguintes categorias profissionais de saúde de nível superior para fins de atuação do Conselho). Brasília, Conselho Nacional de Saúde. Disponível em www.crefrs.org.br/legislacao/pdf/resol_cns_287_1998.pdf, consultado em 5/9/2011.

Diniz, Marli. (2001) Os donos do saber: profissóes e monopólios profissionais. Rio de Janeiro, Revan.

Freidson, Eliot. (2009), Profissão médica: um estudo de sociologia do conbecimento aplicado. São Paulo/Porto Alegre, Editora da Unesp/Sindicato dos Médicos.

Girardi, Sábado Nicolau; Fernandes JR., Hugo; CARVAlho, Cristiana Leite. (2000), "A regulamentação das profissões de saúde no Brasil". Revista Espaço para a Saúde, $1(2): 1-21$.

Laplantine, F. (1991), Antropologia da doença. São Paulo, Martins Fontes.

MaCHado, Maria Helena (org). (1995), Profissóes de saúde: uma abordagem sociológica. Rio de Janeiro, Fiocruz.

Ministério da SAÚde. (s. d.), "Cadastro Nacional de Estabelecimentos de Saúde". Brasília, Datasus/Secretaria de Atenção à Saúde/Ministério da Saúde. Disponível em cnes.datasus.gov.br/Index.asp, consultado em maio 2014.

Ministério do Trabalho e Emprego - mte. (s. d.), "Classificação Brasileira de Ocupações”. Brasília, Ministério do Trabalho e Emprego. Disponível em www.mtecbo. gov.br/cbosite/pages/home.jsf, consultado em 15/11/2011.

NASCimento, Juliana Luporini. (2011), Uma (con)figuração: cientistas sociais, antropólogos, sociólogos e cientistas politicos em saúde no Brasil. Tese de doutorado. Campinas, FCM-Unicamp.

Nunes, Everardo Duarte. (2003), “A sociologia da saúde nos Estados Unidos, Grã-Bretanha e França: panorama geral”. Ciênc. Saúde Coletiva, 8 (1): 79-95.

. (2006), "A trajetória das ciências sociais em saúde na América Latina: revisão da produção científica". Rev. Saúde Pública, 40: 64-72

. (1992) "As ciências sociais em saúde: reflexões sobre as origens e a construção de um campo de conhecimento". Saúde Soc., 1 (1): 59-84.

. (2000), "Ensinando Ciências Sociais em uma escola de medicina: a história de um curso (1965-90)”. História Ciências Saúde - Manguinhos, 6 (3): 631-657.

Nunes, Everardo Duarte; BARros, Nelson Filice; NAscimento, Juliana Luporini \& 
Montagner, Maria Inêz. (2005), “Os profissionais em ciências sociais e humanas em saúde”. Relatório de pesquisa. Campinas, Unicamp.

PATHAK, Archana. (2013), “Musings on postocolonial autoetnography”. In: Holman, Stacy Jone; ADAMS, Tony E. \& ELLIS, Carolyn (orgs.). Handbook of autoetnography. Walnut Creek, CA, Letft Coast Press.

SChWARTZMan, Simon. (2011), "A sociologia como profissão pública no Brasil". In: Dwyer, Tom; Villas BôAs, Glaucia \& SCAlon, Celi (orgs). Consensos e controvérsias. Porto Alegre, Tomo Editorial (série Sociologia das Conflitualidades, n. 5).

SENNETT. Richard. (2012), Juntos: os rituais, os prazeres e a politica da cooperação. Rio de Janeiro, Record.

STRAUSs, Robert. (1957), "The nature and status of medical sociology”. Amer. Soc. Ver., 22 (2): 200-204.

Teixeira, Márcia de Oliveira. (2004), "O trabalho e a pesquisa em saúde: notas sobre a invisibilidade do trabalho técnico". Ciênc. Saúde Coletiva, 9 (3): 785-794.

World Health Organization - Who. (2013), "A universal truth: no health without a workforce”. Genebra, World Health Organization. Disponível em www. who.int/workforcealliance/knowledge/resources/GHWA_AUniversalTruthReport. pdf, consultado em maio 2014.

70 Tempo Social, revista de sociologia da USP, v. 27, n. 1 


\section{Resumo}

Cientistas sociais no Sistema Único de Saúde

Embora exista uma tradição de cientistas sociais atuando no campo da saúde no Brasil, essa força de trabalho e suas contribuições são praticamente invisíveis. O objetivo deste artigo é discutir os resultados de duas investigações complementares, realizadas nos 645 municípios do estado de São Paulo, a fim de compreender a visão dos gestores de saúde e de cientistas sociais sobre o trabalho desses gestores no Sistema Único de Saúde (SUS). Concluiu-se que o ingresso para o trabalho no campo da saúde não é planejado e que a condição de invisibilidade, colonização e estranhamento dessa força de trabalho é promovida pelas internalidades tanto do campo da saúde como do campo das ciências sociais. Palavras-chave: Sociologia da saúde; Trabalho; Invisibilidade social; Sociologia de grupos profissionais.

\section{Abstract}

Social scientists in the Brazil's National Health Service

Although there is a tradition of social scientists working in the health sector in Brazil, the workforce and its contribution remains almost completely invisible. This article discusses the results of two complementary investigations, conducted in 645 municipalities in São Paulo state, into the views of healthcare managers and social scientists concerning their work in Brazil's National Health System. The study concludes that the entry to work in the health sector is unplanned and that the invisibility, colonization and alienation of this workforce are generated by internal factors within both the health sector and the social sciences themselves.

Keywords: Sociology of Health; Work; Social invisibility; Sociology of professional groups.

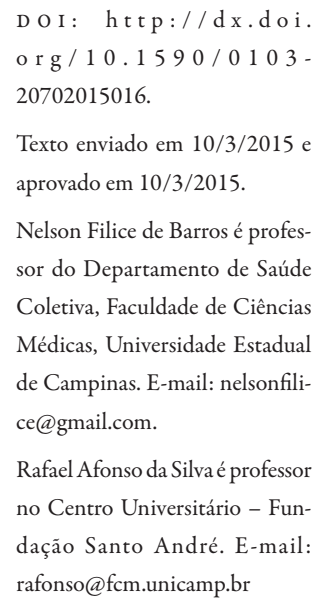


